\title{
Maternal Hemoglobin Concentration and Pregnancy Outcome: A Study of the Effects of Elevation in El Alto, Bolivia
}

\author{
Elise M. Laflamme*
}

\begin{abstract}
Iron-deficiency anemia is often under-diagnosed in developing countries, specifically in pregnant populations in regions of high altitude. Hemoglobin levels are not consistently adjusted for elevation, and therefore many anemic patients are left undiagnosed. The purpose of this study was to incorporate current parameters for diagnosing anemia in pregnancy at high altitudes, and to evaluate the effects of appropriately adjusted hemoglobin concentrations on pregnancy outcome. A few studies have examined the effect of elevation on hemoglobin status, and other studies have considered the effects of anemia of pregnancy; however, there is a lack of data demonstrating that altitude-adjusted hemoglobin levels accurately predict pregnancy outcome. Using the Student t-Test, multiple linear regression, and ANOVA statistical analyses, various factors of pregnancy outcome were compared between anemic and non-anemic groups, as defined by hemoglobin cut-off levels adjusted for trimester of pregnancy and altitude. When appropriate adjustments were used, maternal anemia was associated with lower infant Apgar scores at both one minute and five minutes after birth, as well as complication of labor, lower gestational age at birth, and higher parity. This study demonstrates the importance of altitude and trimester specific adjustments to maternal hemoglobin levels in order to accurately diagnose anemia in pregnancy. In addition, a clear correlation is seen between maternal hemoglobin level and pregnancy outcome.
\end{abstract}

KEYWORDS: Iron-Deficiency Anemia, Pregnancy, Bolivia, Elevation, Altitude, Hemoglobin

\section{INTRODUCTION}

Iron-deficiency anemia is a health problem that often goes untreated, especially in pregnant women living in developing countries, where it can be most dangerous. The World Health Organization (WHO) estimates that an average of $56 \%$ of pregnant women in developing countries are anemic. 1 This percentage ranges from $35-75 \%$ in specific areas, and is much higher than the $18 \%$ of pregnant women diagnosed with anemia in developed

*To whom correspondence should be addressed: Elise Laflamme

9 Chequeset Road, Worcester, Massachusetts 01605 Telephone (978) 500-3628

Email: Elise.Laflamme@umassmed.edu countries (1). Iron deficiency during pregnancy is thought to be caused by combination of factors such as previously decreased iron supply, the iron requirements of the growing fetus, and expansion of maternal plasma volume (2). While plasma volume and red blood cell mass are both known to expand during pregnancy, plasma volume grows to a greater extent, therefore diluting the maternal hemoglobin concentration $(\mathrm{Hb})(3)$. It is necessary to take this into consideration when diagnosing anemia in pregnant women. Effective diagnosis has been achieved by laboratory tests of hemoglobin and hematocrit (Hct) levels. However, it is also necessary to identify precise cut-offs for anemia ac- 
cording to age and current trimester of pregnancy. Research has found that $\mathrm{Hb}$ and Hct concentrations typically decrease during the first trimester, reach the lowest levels at the end of the second trimester, and increase again during the third trimester of pregnancy (4). The Center for Disease Control (CDC) has used this research to establish trimester-specific $\mathrm{Hb}$ concentration adjustments for diagnosing anemia in pregnancy (Table 1). Hemoglobin adjustments for an unknown trimester dating have been developed by the WHO (5).

Hemoglobin levels have also been known to vary in response to altitude. Elevations of over 1000 meters increase patient $\mathrm{Hb}$ levels (3). This is known as an adaptation response to the lower partial pressure of oxygen, which causes reduced oxygen concentration in the blood. The body responds to this change by increasing $\mathrm{Hb}$ concentration in order to ensure that oxygen transport is sufficient for tissues requirements (3). This $\mathrm{Hb}$ increase can ultimately mask anemia if it is not carefully considered (6). In order to determine $\mathrm{Hb}$ concentration cut-off levels for anemia at varying altitudes, the CDC Pediatric Nutrition Surveillance System2 has used data from a study of children with little or no iron deficiency. Using this data, they developed a curve of $\mathrm{Hb}$ concentrations as altitude changed, demonstrating the following association between altitude and $\mathrm{Hb}$ :

$\mathrm{Hb}=-.32$ * (altitude in meters $\left.{ }^{*} 0.0033\right)+0.22$ * (altitude in meters ${ }^{*} 0.0033$ )

Although the $\mathrm{Hb}$ adjustment curve developed by the CDC is currently used internationally, it was not developed with the specificity for use in pregnancy. For this reason, studies that confirm or refute the usefulness of this adjustment curve in the pregnant population are necessary.

In addition, it is evident that the effects of maternal anemia on the outcome of pregnancy are not completely understood (1). A U-shaped association has been found between the maternal $\mathrm{Hb}$ level and the birth weight of the infant. High $\mathrm{Hb}$ concentration has been associated with inadequate

\begin{tabular}{|c|c|}
\hline Trimester of Pregnancy & $\begin{array}{c}\text { Hemoglobin } \\
\text { Adjustment }(\mathbf{g} / \mathrm{dL})\end{array}$ \\
\hline First & $-1.0 \mathrm{~g} / \mathrm{dL}$ \\
\hline Second & $-1.5 \mathrm{~g} / \mathrm{dL}$ \\
\hline Third & $-1.0 \mathrm{~g} / \mathrm{dL}$ \\
\hline Unknown Trimester & $-1.0 \mathrm{~g} / \mathrm{dL}$ \\
\hline
\end{tabular}

Table 1: Hemoglobin adjustments for pregnant women at sea level plasma volume expansion, often leading to a lower birth weight or other adverse pregnancy outcomes (7-8). Low birth weight can also be associated with maternal anemia due to preterm labor induced by low $\mathrm{Hb}$ levels $(1,9)$. Data shows that anemia early in pregnancy is associated with increased risk of preterm premature rupture of membranes, while anemia later in pregnancy is associated with spontaneous premature labor (9). Furthermore, it is worthwhile to note the many short-term and longterm outcomes associated with preterm infants born with a low birth weight, such as cerebral palsy, blindness, deafness, hydrocephaly, diabetes, hypertension, and heart disease (10). Finally, there is a positive correlation between Apgar scores and maternal $\mathrm{Hb}$ concentrations, as well as treatment with iron supplement (11-12). Multiple pregnancies and low socioeconomic class are additional risk indicators for iron-deficiency anemia (8). In order to improve prenatal health, additional research is necessary to confirm previous associations. It is crucial that these associations between maternal anemia and pregnancy outcome be explored under appropriate adjustments to hemoglobin cut-off levels in areas of high elevation.

Although most cases of anemia in pregnancy are caused by iron deficiency (13) other types of anemia must also be considered in the diagnosis. These include pure red cell aplasia, aplastic anemia, paroxysomal nocturnal hemoglobulinemia, and myelodysplastic syndrome (13). The classification of various types of anemia is based upon origin and morphology of red blood cells. Origin is classified based on bleeding, increasing destruction of blood cells, and decreased production of cells. Morphology is classified by cell size, shape and color. Based on these classifications, anemias are placed in categories of macrocytic or nomochromic anemias (B12 deficiency or folate deficiency), microcyic of hypochromic anemias (iron deficiency, sideroblastic, or thalassemia anemia), or normocytic or normochromic anemias (aplastic, hemolytic, chronic disease, or sickle cell) (14).

There are many women with iron-deficiency anemia that are not aware of their condition. Iron-deficiency ranges from iron depletion, which causes no physiological harm to the patient, to irondeficiency anemia, which can cause multiple organ failure syndrome, impaired cognitive performance, immunosuppression, physical weakness, impaired gastrointestinal function, and altered hormone production and metabolism (5). Iron-deficiency anemia can be diagnosed accurately if the $\mathrm{Hb}$ concentration of the patient rises after routine iron supple- 
mentation (8). Although iron-deficiency anemia is the most common type of anemia diagnosed, the various other types of anemia must also be considered when diagnosing a patient with iron-deficiency anemia.

Iron supplementation during pregnancy has been implicated around the world in hopes of increasing the iron supply of anemic patients. Studies demonstrate that these supplements can increase infant birth weight (15-16). A Nigerian study on iron supplementation during pregnancy found that iron supplements could also increase Apgar scores of infants (1). Other studies show that supplements do not consistently decrease the incidence of iron-deficiency anemia in women that have entered pregnancy with low $\mathrm{Hb}$ levels and low iron stores. More specifically, some research illustrates that anemia in pregnancy can only be reduced if supplementation is initiated before conception (17). Regardless of varying study outcomes, many share the opinion that we should practice routine iron supplementation during pregnancy, most importantly to anemic pregnant women (1).

The purpose of this study was to evaluate the effect of trimester and altitude-adjusted $\mathrm{Hb}$ levels on and pregnancy outcome. Although the effects of altitude on $\mathrm{Hb}$ concentration is established, many patients in developing countries remain undiagnosed with anemia due to failure to apply these $\mathrm{Hb}$ adjustments. In this study we provide data that demonstrates that the application of altitude-specific $\mathrm{Hb}$ adjustments for anemia is useful in the prediction of pregnancy outcome. Additionally, we determine which specific aspects of pregnancy outcome are most affected by maternal $\mathrm{Hb}$ concentration in the population of pregnant women in El Alto, Bolivia, when $\mathrm{Hb}$ is appropriately adjusted for the effects of elevation.

\section{METHODS}

Study Cohort:

This study was carried out in May 2006 in El Alto, Bolivia, at the Los Andes Hospital. This institution is a small hospital which services mothers and children. El Alto is a growing city of over 500,000 people, found at an altitude of 4018 meters above sea-level (18). The the study was approved by Northeastern University's Director of Research Integrity. Review by the FDA's Institutional Review Board was waived by Northeastern, as work was done under the direction of Dra. Cecilia Uribe de Chavez, the local Medical Director of Child and Family Health International. Consent to review patient charts was given by Dra. Uribe. Subjects were randomly chosen as they gave birth in the hospital, and charts were reviewed after verbal consent by patients. Only subjects with complete data were included in the study.

Ninety-eight patient charts were reviewed by a Spanish interviewer. Patient information was transcribed to a data collection sheet, which included patient parity, weight, height, hemoglobin and hematocrit levels, infant birth weight, length, head circumference, gestational age, Apgar scores, and any other complications in pregnancy. Gestational age was quantified as the number of weeks between the patients' last recalled menstrual period and the day of delivery.

\section{Hemoglobin measurement:}

Hemoglobin levels were categorized as "anemic" and "non-anemic," according to The World Health Organization's accepted values to define anemia, along with the adjustments provided by the CDC to determine anemia during pregnancy. Averages of pregnancy number (parity), gestational age, birth weight, birth length, head circumference and Apgar scores at 1 and 5 minutes were calculated for both "anemic" and "non-anemic" patients. These averages were analyzed for statistically significant relationships with $\mathrm{Hb}$ levels using the $\mathrm{t}$ TEST in Microsoft Excel Data Analysis Toolpack.

Hemoglobin concentrations were sorted into four categories of $1.99 \mathrm{~g} / \mathrm{dL}$ per category, ranging from $7.00 \mathrm{~g} / \mathrm{dL}$ to $14.99 \mathrm{~g} / \mathrm{dL}$. Categories were labeled based on the CDC's trimester-specific cutoff level for anemia in pregnancy as High-Normal $(13.00-14.99 \mathrm{~g} / \mathrm{dL})$, Normal $(11.00-12.99 \mathrm{~g} / \mathrm{dL})$, Mild (9.00-10.99 g/dL), Moderate $(7.00-8.99 \mathrm{~g} / \mathrm{dL})$, and Severe anemia $(<7.00 \mathrm{~g} / \mathrm{dL})$. Hb levels above $14.99 \mathrm{~g} / \mathrm{dL}$ and below $7.00 \mathrm{~g} / \mathrm{dL}$ were considered extraneous and unusable in our study due to the few data points found in these ranges. Using this data in our analysis would have caused unequal group sizes. Means of collected data for pregnancy outcome factors were calculated for each category.

Hemoglobin adjustment was calculated by subtracting the adjustment value from the measured $\mathrm{Hb}$ concentration at the relevant altitude, to the nearest 500 meters, in order to obtain the comparative sea-level value. The increase in $\mathrm{Hb}$ concentration due to elevation and lower atmospheric partial pressure is often misinterpreted as a sign of sufficient iron status, while a patient from a highaltitude area may actually have iron-deficiency anemia. It is important to determine whether women with apparently normal $\mathrm{Hb}$ levels at high elevation are actually anemic and whether or not these seem- 


\begin{tabular}{|l|c|c|c|}
\hline \multicolumn{1}{|c|}{ Variable } & n & Mean \pm SD & Median \\
\hline Age, years & 98 & $27.20 \pm 6.90$ & 26.0 \\
\hline Height, $\mathrm{cm}$ & 74 & $148.40 \pm 6.20$ & 148.0 \\
\hline Weight, $\mathrm{kg}$ & 80 & $56.00 \pm 9.80$ & 55.1 \\
\hline Weight at Birth, $\mathrm{kg}$ & 65 & $65.10 \pm 9.60$ & 64.5 \\
\hline BMl, $\mathrm{kg} / \mathrm{m}^{2}$ & 51 & $29.50 \pm 4.40$ & 30.1 \\
\hline Maternal Hb, $\mathrm{g} / \mathrm{dL}$ & 79 & $12.97 \pm 2.07$ & 13.4 \\
\hline $\begin{array}{l}\text { Maternal Hb (altitude-adjusted), } \\
\text { g/dL }\end{array}$ & 79 & $12.61 \pm 2.08$ & 13.0 \\
\hline Infant Gestational Age, weeks & 94 & $38.50 \pm 2.10$ & 39.0 \\
\hline Infant Birth Weight, $\mathrm{g}$ & 97 & $3,200 \pm 500$ & 3,300 \\
\hline Infant Birth Length, $\mathrm{cm}$ & 95 & $47.76 \pm 4.30$ & 49.0 \\
\hline Infant Head Circumference, $\mathrm{cm}$ & 95 & $37.90 \pm 31.90$ & 34.8 \\
\hline Apgar Score, $1 \mathrm{~min}$ & 95 & $7.40 \pm 1.30$ & 8.0 \\
\hline Apgar Score, 5 min & 95 & $9.00 \pm 1.40$ & 9.0 \\
\hline Parity & 75 & $1.80 \pm 1.90$ & 1.0 \\
\hline
\end{tabular}

Table 2: Characteristics of the study population, El Alto, Bolivia

ingly normal $\mathrm{Hb}$ concentrations, after adjusting for elevation, actually serve as a risk factor for poor pregnancy outcome. Based on previous research and suggested $\mathrm{Hb}$ adjustment values (4), we subtracted $0.34 \mathrm{~g} / \mathrm{dL}$ from all patients' $\mathrm{Hb}$ concentrations in order to consider the effects of altitude.

In this study, anemia is defined as a $\mathrm{Hb}$ level lower than the "Normal" ( $<11.0 \mathrm{~g} / \mathrm{dL}) \mathrm{Hb}$ level at the defined altitude. $\mathrm{Hb}$ concentrations during pregnancy are generally lower due to the maternal plasma expansion, along with the growing fetus's use of the maternal iron stores (2).

For these reasons, data in this study was used only if maternal $\mathrm{Hb}$ concentration was analyzed before the end of the first trimester of pregnancy. Studies have concluded that $\mathrm{Hb}$ cutoff levels to define anemia in non-pregnant females above the age of fifteen should be $12.0 \mathrm{~g} / \mathrm{dL}$ (3). Furthermore, the CDC has developed trimester-specific cutoff level adjustments for pregnant women. These can be calculated by trimester by subtracting values as in Table 1.4 The blood tests used to determine patient $\mathrm{Hb}$ levels in this study were run during the first trimester of pregnancy, and therefore the cutoff level used for identifying anemia was $11.0 \mathrm{~g} / \mathrm{dL}$.

\section{Statistical analysis:}

Multiple linear regression analysis was used to determine the effect of $\mathrm{Hb}$ levels on factors of pregnancy outcome, considering any confounding variables that may influence both $\mathrm{Hb}$ levels and outcomes. Pregnancy outcome factors analyzed by this regression included gestation age, Apgar scores at 1 and 5 minutes following birth, and birth weight of infant. Parity was also examined as a possible determinant of $\mathrm{Hb}$ concentration using this analysis. Regression was applied using Microsoft Excel Data Analysis Toolpack.

Using SPSS 14.0.1 for Windows, ANOVA (ANalysis Of VAriance between groups) was applied to determine the statistically significant difference between the means of the four categories. Further post hoc Tukey honest significant difference (HSD) analysis $(P<0.05)$ was applied to all data analyzed in the ANOVA.

\section{RESULTS}

Study cohort:

This study included 98 women (Table 2). Descriptive variables of maternal health and variables of pregnancy outcome were analyzed from the available data. The average age of the women evaluated was 27.2 years, while the median age was 26.0 years. The majority of the women were from El Alto (82), while the others were from the nearby areas of La Paz, Polochoco, Alto Lima, Challahuyo, Guayuyo, Yuayayo, Achacadi, Puerto de Gui Gui, and Brosil.

The average hemoglobin concentration of the subjects was $12.965 \mathrm{~g} / \mathrm{dL}$, which was adjusted to $12.609 \mathrm{~g} / \mathrm{dL}$ using the Center for Disease Control

\begin{tabular}{|l|c|c|c|}
\hline & ANEMIC & NON-ANEMIC & P VALUE \\
\hline $\mathrm{Hb}, \mathrm{g} / \mathrm{dL}$ & 9.31 & 13.7 & $1.16 \mathrm{e}^{-08}$ \\
\hline $\mathrm{Hb}$ (altitude-adjusted), $\mathrm{g} / \mathrm{dL}$ & 8.97 & 13.4 & $1.19 \mathrm{e}^{-09}$ \\
\hline Gestation Length, weeks & 37.1 & 38.9 & 0.059 \\
\hline Birth Weight, $\mathrm{g}$ & $3.10 \mathrm{e}^{03}$ & $3.30 \mathrm{e}^{03}$ & 0.213 \\
\hline Birth Length, $\mathrm{cm}$ & 47.8 & 47.5 & 0.431 \\
\hline Head Circumference, $\mathrm{cm}$ & 34.2 & 39.5 & 0.137 \\
\hline Apgar, 1 minute & 5.90 & 7.60 & 0.006 \\
\hline Apgar, 5 minute & 7.80 & 9.20 & 0.039 \\
\hline Parity & 4.10 & 1.50 & 0.010 \\
\hline Birth Complications & $64.3 \%$ with complications & $15.4 \%$ with complications & 0.002 \\
\hline
\end{tabular}

Table 3: Comparison of means between pregnancy outcome in anemic and non-anemic pregnant women $(n=80)$ 
and Prevention's anemia criteria and altitude adjustment (19).

\section{Hemoglobin levels:}

Based on the altitude and pregnancy-adjusted $\mathrm{Hb}$ concentrations, 14 of the 80 pregnant women were defined as anemic (17.5\%). The means of various factors of pregnancy outcome between anemic and non-anemic groups were compared (Table 3 ) and statistically significant differences were assessed using Student's t-TEST. Maternal anemia was associated with lower infant Apgar scores at both 1 and 5 minutes after birth. The stronger relationship was observed in the effects of anemia on low Apgar scores at 1 ( $P=$ $0.006)$, versus at 5 minutes $(P=0.039)$.

\section{Birth complications:}

Birth complications were more prevalent in anemic women than in non-anemic women. In this study, any major deviation from normal, healthy labor was considered a "complication." A patient was considered positive for birth complications if she underwent an emergency cesarean section, experienced preeclampsia, if the infant needed oxygen through a facemask, or was stillborn. While $64.3 \%$ of anemic subjects experienced some type of birth complications, only $15.4 \%$ of non-anemic subjects faced these problems. Women who experienced birth complications were assigned the categorical value of " 1, " and women with no complications were assigned a value of " 0. " These categorical values represent the possible outcomes, while the anemic and non-anemic categories represent the variables. A t-TEST was run with this data, and showed a strong correlation between maternal anemia and complications in birth $(P=0.002)$.

\section{Parity, gestational age, and birth weight:}

Higher parity was associated with anemia, with 4.1 previous pregnancies in anemic women compared to 1.5 previous pregnancies in non-anemic women $(P=0.010)$. Although the average gestational age of infants born to anemic women was nearly two weeks less than that of infants born to non-anemic women, this difference failed to reach statistical significance $(P=0.059)$. Average birth weight of infants of anemic patients was $210 \mathrm{~g}$ less than the average birth weight of those of non-anemic patients, however, no statistical significance was observed $(P=0.213)$.

\section{Pregnancy outcome:}

Complete data for both $\mathrm{Hb}$ concentrations and all evaluated pregnancy outcome factors were available for a total of 56 woman-infant pairs. Multiple linear regression was used to assess the relationship between maternal $\mathrm{Hb}$ levels and the various predictors of pregnancy outcome. All measured outcomes of pregnancy were included in the regression model. Using this multivariate regression, there was a statistically significant association between $\mathrm{Hb}$ level and gestation age $(P=0.0284)$, the Apgar score at 1 minute $(P=0.00039)$ and at 5 minutes $(P=0.018)$, as well as parity $(P=0.00082)$. This data may suggest that women with higher parity are more likely to become anemic, or that women with multiple births did not have sufficient time to recover their hemoglobin stores following their previous pregnancies. Additional studies may be beneficial in determining the exact association, and the supporting physiology, between parity and consequent hemoglobin levels.

Patient stratification based on hemoglobin concentration:

Subjects were divided into six groups based on their maternal $\mathrm{Hb}$ level (Table 4). The means of various pregnancy outcomes were calculated for each $\mathrm{Hb}$ category. In further analysis, only data from subjects with $\mathrm{Hb}$ concentrations between $7.00 \mathrm{~g} / \mathrm{dL}$ and $14.99 \mathrm{~g} / \mathrm{dL}$ were used, as there were

\begin{tabular}{|c|c|c|c|c|c|c|c|}
\hline $\mathbf{H b}, \mathbf{g} / \mathbf{d L}$ & $\mathbf{n}$ & \multicolumn{5}{|c|}{ MEANS OF PREGNANCY OUTCOME FACTORS } \\
\hline & & $\mathbf{H b}, \mathbf{g} / \mathbf{d L}$ & $\begin{array}{c}\text { Birth } \\
\text { Weight, } \boldsymbol{g}\end{array}$ & $\begin{array}{c}\text { Apgar, } \\
\mathbf{1} \text { min }\end{array}$ & $\begin{array}{c}\text { Apgar, } \\
\mathbf{5} \text { min }\end{array}$ & $\begin{array}{c}\text { Gestation, } \\
\text { weeks }\end{array}$ & Parity \\
\hline $7.00-8.99$ & 7 & 8.25 & 2,950 & 4.750 & 6.50 & 37.60 & 3.65 \\
\hline $9.00-10.99$ & 6 & 10.26 & 3,006 & 6.875 & 8.75 & 36.50 & 5.75 \\
\hline $11.00-12.99$ & 20 & 11.97 & 3,231 & 7.357 & 9.05 & 38.40 & 1.85 \\
\hline $13.00-14.99$ & 41 & 13.99 & 3,208 & 7.761 & 9.35 & 39.10 & 1.27 \\
\hline
\end{tabular}

Table 4: Categorical $\mathrm{Hb}$ levels and associated means of pregnancy outcome factors $(n=74)$ 


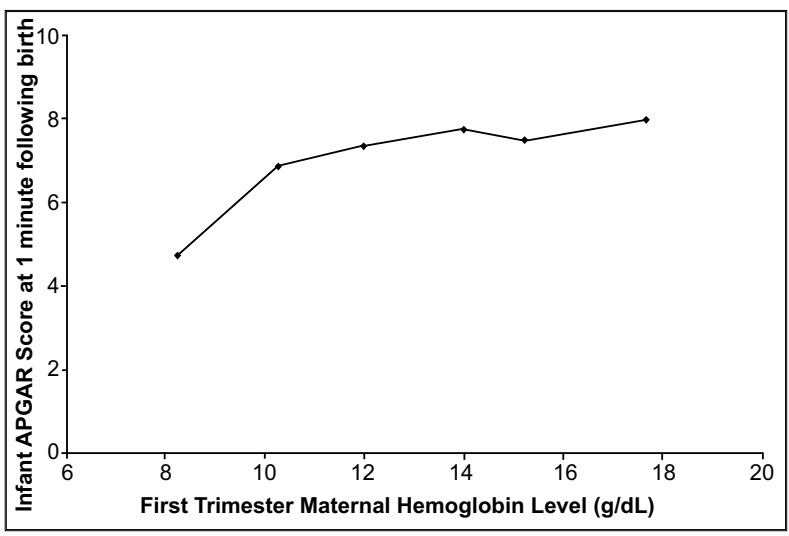

Figure 1a: Effects of first trimester materinal hemoglobin level $(\mathrm{g} / \mathrm{dl})$ on infant health, as measured by APGAR socre at 1 minute following birth $(n=74)$. All measurements taken in El Ato, Bolivia, elevation 4018 meters above sea level.

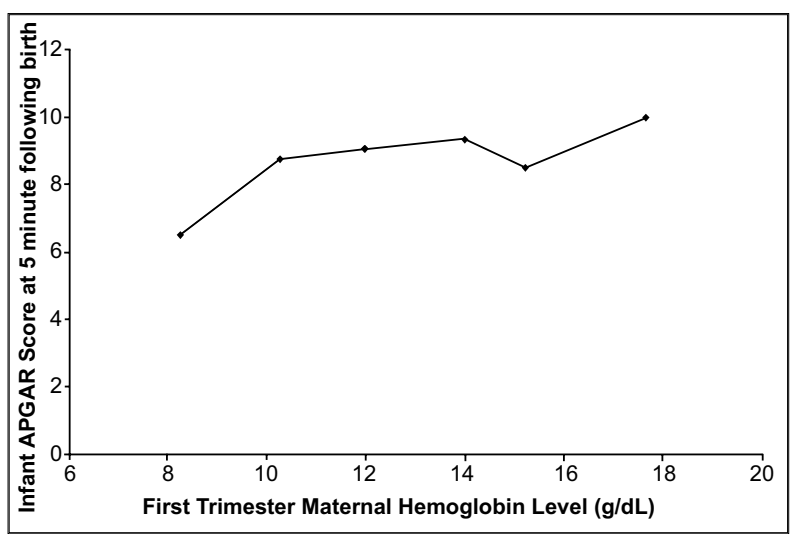

Figure 1b: Effects of first trimester materinal hemoglobin level $(\mathrm{g} / \mathrm{dl})$ on infant health, as measured by APGAR socre at 5 minute following birth $(n=74)$. All measurements taken in El Ato, Bolivia, elevation 4018 meters above sea level.

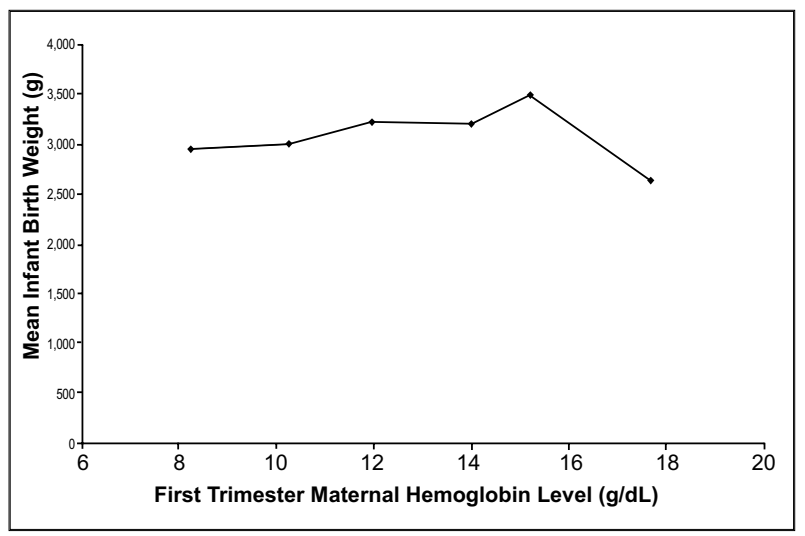

Figure 2: Effects of first trimester materinal hemoglobin level $(\mathrm{g} / \mathrm{dl})$ on infant health, as measured by mean infant birth weight (g) $(n=74)$. All measurements taken in El Ato, Bolivia, elevation 4018 meters above sea level. not enough data in the upper categories to make statistically significant conclusions.

When mean Apgar scores recorded at 1 minute were plotted against the Hb groups, Apgar scores appear to increase gradually from low to high maternal $\mathrm{Hb}$ levels (Figure 1a). At lower $\mathrm{Hb}$ levels, Apgar score increases significantly as maternal $\mathrm{Hb}$ levels increase. At higher maternal $\mathrm{Hb}$ levels, Apgar scores tend to increase less drastically and the trend curve levels off. When plotting $\mathrm{Hb}$ groups against Apgar scores at 5 minutes after birth, a similar trend is observed (Figure 1b). However, the curve formed from this data includes a point that falls off the apparent trend line $(\mathrm{at} \mathrm{Hb}$ concentrations of $15.21 \mathrm{~g} / \mathrm{dL}$.)

Average birth weight of the infants also showed a slight increase as $\mathrm{Hb}$ concentrations increased (Figure 2). The point on this plot referring to mean $\mathrm{Hb}$ of $17.66 \mathrm{~g} / \mathrm{dL}$ demonstrates that the $\mathrm{U}$-shaped association between $\mathrm{Hb}$ concentration and birth weight (Figure 2) may be present weakly within our data.

ANOVA analysis of pregnancy outcomes and $\mathrm{Hb}$ levels:

ANOVA analysis was used to evaluate these observed trends. Subjects with $\mathrm{Hb}$ concentrations below $7.00 \mathrm{~g} / \mathrm{dL}$ and above $14.99 \mathrm{~g} / \mathrm{dL}$ were not included in the ANOVA analysis. The analysis confirmed that correlations between differences in increasing $\mathrm{Hb}$ concentrations and gestation length were statistically significant $(P=0.007)$. When this method was used to evaluate the relationship between increasing $\mathrm{Hb}$ levels and infant birth weight, no statistically significant differences were present $(P=0.458)$. However, statistical significance was identified in the relationship between increasing $\mathrm{Hb}$ levels and infant Apgar scores at 1 minute $(P=$ $0.000)$, and at 5 minutes $(P=0.002)$, and parity $(P$ $=0.000$ ).

Post hoc Tukey HSD analysis of pregnancy outcomes and $\mathrm{Hb}$ levels:

Using the same data and same four $\mathrm{Hb}$ groups (7.00-8.99 g/dL, 9.00-10.99 g/dL, 11.00$12.99 \mathrm{~g} / \mathrm{dL}$, and $13.00-14.99 \mathrm{~g} / \mathrm{dL}$ ), the ANOVA analysis was further developed with an post hoc Tukey HSD analysis. When examining gestation length as a dependent variable, subjects with mild anemia (Hb 9.00-10.99 g/dL) had significantly lower gestational lengths $(P<0.05)$ than groups those of the Normal (11.00-12.99 g/dL) and High-Normal $(13.00-14.99 \mathrm{~g} / \mathrm{dL})$ groups, which are statistically equal to the Moderate anemia group (7.00-8.99 g/dL). 
In comparing $\mathrm{Hb}$ groups with respect to the infants' Apgar scores at 1 minute following birth, the Moderate anemia group had lower scores than the Normal and High-Normal groups, which were statistically equal to the Mild Anemia group. When Tukey's HSD analysis was repeated with Apgar scores at 5 minutes following birth, the same relationships were observed as in Apgar scores at 1 minute. Finally, parity in the Mild and Moderate anemia subjects was found to be significantly greater than in the Normal and High-Normal group subjects.

\section{DISCUSSION}

This study demonstrates the importance of using $\mathrm{Hb}$ cut-off levels specific to elevation in the diagnosis of iron-deficiency anemia. As illustrated in the data, $17.5 \%$ of the pregnant study population from El Alto can be diagnosed with maternal anemia using diagnostic cut-off levels adjusted for elevation. Without using these adjusted $\mathrm{Hb}$ levels, only $11.39 \%$ of the study population would be diagnosed with anemia, and $6.11 \%$ of the study population would be left undiagnosed and untreated for the condition. It is very likely that this undiagnosed percentage translates into a large number of women in the El Alto population who are left untreated for anemia in pregnancy due to insufficient use of altitude-adjusted hemoglobin levels.

Furthermore, this study should be used as an evaluation of various factors of pregnancy outcome in relation to maternal $\mathrm{Hb}$ adjusted for elevation. The data demonstrate that maternal anemia was significantly associated with the health of the infant at birth, and that anemic pregnant women gave birth to infants with lower Apgar scores at 1 and 5 minutes following birth than healthy pregnant women. In addition, the prevalence of birth complications in women with maternal anemia was significantly higher than in non-anemic women. The gestation age of the infants was not statistically different between anemic and non-anemic mothers. However, the average gestation age of women with anemia was approximately two weeks less than the average gestation of non-anemic women. The average infant birth weight of women with maternal anemia was 210 grams less than that of women without maternal anemia; however, no statistical significance was determined between the two.

Given the results of the study, it is evident that public awareness of iron-deficiency anemia and its adverse effects must be increased in developing countries. Prenatal care and education from medical professionals is crucial in improving the health of the mother and the developing fetus dur- ing pregnancy. Women in all regions of the world need to be taught the importance of this medical care, as well as the value of adherence to vitamin supplementation.

There are still major gaps to bridge in regards to the awareness and treatment of anemia and other health conditions during pregnancy. Using current knowledge, additional studies and effective implementation, public understanding is achievable. Public information sessions and education programs regarding health care during pregnancy and infancy may improve knowledge in El Alto and should be prioritized in the future.

In conclusion, this study sheds light on the fact that the application of altitude-specific hemoglobin adjustments for the diagnosis of anemia is useful in the prediction of pregnancy outcome. Using these adjustment methods, maternal anemia in El Alto, Bolivia, is strongly associated with lower infant Apgar scores at both 1 and 5 minutes following birth, as well as shorter gestational length and higher parity. It is imperative that additional research is done to determine ways to enforce the usage of adjusted $\mathrm{Hb}$ cutoffs in pregnancy, most importantly in areas of high elevation. If these cutoffs are correctly used, we can decrease worldwide maternal and infant mortality rates by ensuring that anemic pregnant women receive appropriate medical treatment.

\section{ACKNOWLEDGEMENTS}

The author would like to thank Dr. Daniel Scheirer, Associate Dean of Trinity College at Duke University, for his invaluable assistance as an advisor and advocate for the work presented in this article. In addition, thanks is owed to Child and Family Health International for their assistance in this research. CFHI's Medical Director in La Paz, Dra. Cecilia Uribe de Chavez, was of great help in providing access to hospital records. Furthermore, the author acknowledges the support of Northeastern University professors Dr. Geoffrey C. Trussell, Mikhail Malioutov, DSc., and John Lindhe in the analysis and interpretation of data. Financial assistance from Northeastern University's CEA Way Project Award, Faculty Undergraduate Research Award and Matthews Undergraduate Award was also greatly appreciated. Most importantly, the author would like to thank the women of El Alto, Bolivia, for making this study possible. 


\section{REFERENCES}

1. Allen LH. "Anemia and iron deficiency: effects on pregnancy outcome." The American Journal of Clinical Nutrition. April 2000; 71(suppl):1280S-4S.

2. Cohen JH, Haas JD. "Hemoglobin correction factors for estimating the prevalence of iron deficiency anemia in pregnant women residing at high altitudes in Bolivia." Pan American Journal of Public Health. December 1999; 6.6:392-399

3. Nestel, Penelope. "Adjusting Hemoglobin Values in Program Surveys." International Nutritional Anemia Consultative Group. June 2002.

4. Center for Disease Control. "Current Trends CDC Criteria for Anemia in Children and Childbearing-Aged Women." Morbidity and Mortality Weekly Report. June 9, 1989; 38(22); 400-404.

5. WHO/UNICEF/UNU, ed. "Iron deficiency anaemia, assessment, prevention and control: a guide for programme managers." WHO. 2001.

6. Hinderaker SG, Olsen BE, Bergsjo P, Lie RT, Gasheka P, Kvale G. "Anemia in pregnancy in the highlands of Tanzania." Acta Obstretricia et Gynecologia Scandinavica. 2001; 80:18-26.

7. Murphy JF, O'Riordan J, Newcombe RG, Coles EC, Pearson JF. "Relation of haemoglobin levels in first and second trimesters to outcome of pregnancy." Lancet. May 1986;1(8488):992-995.

8. Lee RL. "Iron Deficiency Anemia." California Department of Health Services; Maternal Child and Adolescent Health Branch. January 2004.

9. Zhang Q, Ananthe CV, Li Z, Smulian JC. "Mathernal anaemia and preterm birth: a prospective cohort study." International Journal of Epidemiology. 2009:38;1380-1389.

10. Rusia U, Madan N, Agarwal N, Sikka M, Sood S. "Effect of maternal iron deficiency anaemia on foetal outcome." Indian Journal of Pathology and Microbiology. 1995;38:273279.

11. Goldenberg RL, Culhane JF. "Low birth weight in the United States." American Journal of Clinical Nutrition. February 2007;85(2):584S-590S.
12. Preziosi P, Prual A, Galan P, Daouda H, Boureima H, Hercberg $\mathrm{S}$. "Effect of iron supplementation on the iron status of pregnant women: consequences for newborns." American Journal of Clinical Nutrition. 1997;66:1178-1182.

13. Dallman PR, Yip R, Johnson C. "Prevalence and causes of anemia in the United States, 1976 to 1980." American Journal of Clinical Nutrition. 1984;39:437-445.

14. Erwin G. "Consultant Pharmacist-Driven Approach to Identification of Anemia of CKD in SNF Residents." American Society of Consultant Pharmacists.

15. Agarwal KN, Agarwal DK, Mishra KP. "Impact of anaemia prophylaxis in pregnancy on maternal haemoglobin, serum ferritin \& birth weight." Indian Journal of Medical Research. August 1991;94:277-80.

16. Hemminki E, Starfield B. "Routine administration of iron and vitamins during pregnancy: Review of controlled clinical trials." Blackwell Journal of Obstetrics \& Gynaecology. June 1978;85(6):404.

17. Khambalia AZ, O'Connor DL, Macarthur C, Dupuis A, Zoltkin SH. "Periconceptional iron supplementation does not reduce anemia or improve iron status amoung pregnant women in rural Bangladesh." American Journal of Clinical Nutrition. November 2009;90(5):1295-1302.

18. Gamponia MJ, Babaali H, Yugar F, Gilman RH. "Reference values for pulse oximetry at high altitude." Archives of Disease in Childhood. May 1998;78:461-465.

19. CDC (1995): Altitude, Hemoglobin Curve and CDC Anemia Criteria which uses the altitude adjustment. Center for Disease Control and Prevention.

20. Desalegn S. "Prevalence of anaemia in pregnancy in Jima town, southwestern Ethiopia." Ethiopian Medical Journal. October 1993;31(4):251-258.

21. Frith-Terhune AL, Cogswell ME, Khan LK, Will JC, Ramakrishnan U. "Iron deficiency anemia: higher prevalence in Mexican American than in non-Hispanic white females in the third National Health and Nutrition Examination Survey, 1988-1994." American Journal of Clinical Nutrition. October 2000;72(4):963-968.

22. Abyad A. "Routine Prenatal Screening Revisited." Health Care For Women International. March 1999;20(2):137-145.

Elise Laflamme (M.D. 2012) received a B.Sc. (Hons) in Biology from Northeastern University in Boston, Massachusetts, in 2008. She is currently a medical student at the University of Massachusetts Medical School and is interested in specializing in Obstetrics and Gynecology upon graduation. 